\title{
David Hume, Miracles and Irrationality
}

\section{Merlina Koseni (Pograzha)}

PhD Candidate, Universiteti "Aleksandër Moisiu” Durrës Email address: mpograzha@gmail.com

\section{Doi:10.5901/ajis.2013.v2n3p103}

\begin{abstract}
Through this article I shall deal with the Hume's idea that is always irrational to believe a story about a miracle happened. David Hume argues that it is not rational to believe the testimony of a miracle. He believes that this conclusion derives from the principle that a prior failure for a specified event occurs rejects the possibility that the witness of the event is telling the truth. In general terms, this means that the witness is always subject to induction. In that way, as the possibility that a miracle happens, is astronomical in its own definition, we should never believe that someone's story proves it. Many critics have dismissed the evidence that Hume gives us and they are based on probability, not to accept the evidence of these miracles without addressing them on a case by case basis. Despite these criticisms, my goal in this article is to try to see this as an evidence of his consistent so long as we keep in mind what are the definitions of Hume on miracles and natural law. Many of these critics are wrong because they do not take into account what Hume means by miracles and natural law and apply its test in inappropriate cases.
\end{abstract}

\section{Introduction}

Hume's argument in the essay 'On the Miracles" doesn't go against the possibility of the existence of miracles, but against the possibility that it may be reasonable to believe a miracle happened in the past. His argument can be summarized as follows: when judging the credibility of a story about an impossible event, the probability of the event must be weighed against the probability that the story may be wrong. The probability of an event is determined by the degree of its conformity to the known laws of nature. The laws of nature are formulated based on a uniform experience. Assuming that a miracle is a violation of the laws of nature, any judgment that an event is miraculous presuposes a judgment is that there is a uniform model of causality with which it is compared, the model that consists of empirical evidence against the occurrence of miracles. Evidence, on the other hand, as shown by the experience is not always reliable. Thus, no report of a miracle would have credibility, as it will always be a uniform experience that is full proof against him, which weighs more than any merit that the witness may have.

Hume quotes: "testimony is sufficient to establish a miracle, unless the testimony be of such a kind, that its falsehood would be more miraculous, than the fact, which it endeavors to establish.... When anyone tells me, that he saw a dead man restored to life, I immediately consider with myself, whether it be more probable, that this person should either deceive or be deceived, or that the fact, which he relates, should really have happened .... If the falsehood of his testimony would be more miraculous, than the event which he relates: then, and not till then, can he pretend to command my belief or opinion (Hume,2007).

Hume argues against the reliability of a miraculous event by reasoning that the faith should be in proportion to what is in accordance with experience. This principle is an axiom to assess any potential faith. By definition, a miracle doesn't agree so much with what experience teaches us. The very low probability of any miracle story to be true depends on the lack of conformity to observe any causal model. Hume's argument is not based on a calculation of chances for an event to be true, but in an analysis of the meaning of miracles.

\section{The Miracle and the Natural Law}

The Hume's opinion on the concept of miracle is well explained in the paragraph 12 of Enquiry 10, part 1: "A miracle is a violation of the laws of nature; and as a firm and unalterable experience has established these laws, the proof against a miracle, from the very nature of the fact, is as entire as any argument from experience can possibly be imagined. ... Nothing is esteemed a miracle, if it ever happen in the common course of nature. It is no miracle that a man, seemingly in good health, should die on a sudden: because such a kind of death ... has ... been frequently observed to happen. But it 
is a miracle, that a dead man should come to life; because that has never been observed, in any age or country. There must, therefore, be a uniform experience against every miraculous event, otherwise the event would not merit that appellation. And as an uniform experience amounts to a proof, there is here a direct and full proof, from the nature of the fact, against the existence of any miracle; nor can such a proof be destroyed, or the miracle rendered credible, but by an opposite proof, which is superior." (Hume,2007)

In this section Hume shows how to understand a miracle, every miracle must ipso facto be an extreme case of an extraordinary event: an event against which there is a very strong test of experience. So, Hume's argument concerning the evidence of extraordinary events - completed before starting this paragraph, and culminating in his maxim immediately after this paragraph - will automatically be applied to any reported miracle story. Hume sees the proof against a miracle as an argument from experience rather than as a priori, and possibly objectionable by a reverse test more than demonstrative. (In the second part, Hume described sometimes the miracle as impossible, but in these cases he means the physical and casual impossibility, rather than the conceptual or logical impossibility.)

Hume sees the miracle as an event that goes against 'natural law'. But if he conceives the 'natural law' as a true universal generalization about how things operate, then a miracle so described would be a contradiction in terms. In fact the most of the use of the term he refers to 'natural laws' moral. The first work in which Hume speaks of physical 'natural law' is the Enquiry, even he does not explain in any part of it what he means exactly by the natural law. It is often assumed that with this term Hume refers to a de facto generalization without exception, but this is a conclusion based mainly on misunderstandings about his theory of causation, which is supposed to mean that there is no causal law beyond "a summary of a uniform past experience. This view is wrong. The general idea is that of an intervention in the natural order, where supernatural actions bring an event that would not have been able to occur in the ordinary course of things. This presupposes that there is a predetermined set of laws that determine how things happen (how things behave) in the absence of any supernatural intervention. Hume does not suggest that the concept of miracle is not coherent, but if so, it would be just an additional tool in the attack that he makes to the religion.

Hume's argument interpretes "the natural law" 'as a description of an constant observed behaviour in nature- even not universally. He uses sometimes the term in that way, as for example into "The Natural History of Religion", in which he speaks about the uniform natural law' for which "few exceptions are found"... (Hume, 1995). There are also lots of other places where he uses the term 'uniform' to mean something less than a strict universality. This sheds light on his claim that "There must ... be a uniform experience against every miraculous event" (Hume, 2007). The discussion of Hume implies a subjective notion of natural law (relative to the experience of the observer) more than an absolute concept (descriptive of what actually happens, observed or not). Hume's interest is to prove if a specified event really happened, not if the event would have been contrary to natural law. Although a subjective natural law cannot be relevant in modern times, at the time of Hume had meanings. In this sense, one that must be satisfied that a person is resurrected after death, has a uniform experience (subjective) for 'law of nature' that such a thing does not happen, but it does not logically exclude that there may be a revival situation beyond my experience. This does not even mean that the resurrection will not be considered a miracle if revivals become a recurring event. Definition of Hume on miracles is that of repeated violations of a natural law, as he stated in this paragraph: "... if a person, claiming a divine authority, ... should order many natural events, which immediately follow upon his command; these might justly be esteemed miracles, because ... nothing can be more contrary to nature than that the voice or command of a man should have such an influence." (Hume, 2007).

At the end of the essay Hume aims at his argument to be applied not only in religuous claims, but on "every thing new, rare, and extraordinary in nature ... that is to be found in the writers of natural magic or alchemy, or such authors, who seem, all of them, to have an unconquerable appetite for falsehood and fable" (Hume. 2007).

\section{Maxim of Hume}

The fact of reporting of unusual events has been identified as a factor that affects the reliability of the evidence reports. Hume then isolates this particular factor, and sees it as balanced on the other side of the scale against the characteristics of the evidence that makes us inclined to believe it. He represents the most extreme case possible of this balancing', where the reported "instead of being only marvellous, is really miraculous; and ... the testimony, considered apart and in itself, amounts to an entire proof; in that case, there is proof against proof, of which the strongest must prevail, but still with a diminution of its force, in proportion to that of its antagonist. (Hume2007).

Here we must point out two important things. First, Hume has addressed so far the miracle as an extreme case of an extraordinary event, and the general principles involved in this treatment did not differ from those that it used for any 
other extraordinary event. Secondly, showing us how it happens the balancing, Hume realized the strength of evidence "considered separately and in itself" - being subjected to a general degree of proof which may be appropriately weighed against the force of an anti-testing which arises from the unusualness of an assumed event. The strongest proof of these two tests "must prevail, but still with a diminution of its force, in proportion to that of its antagonist." So, the credibility we give to the testimony will depend on the extent to which the evidence of the testimony (or on other hand the evidence of the experience) weighs on his antagonist. Hume ponders the logical tie of the evidence, the good character of the witness, the number of witnesses, the convincing way of the distribution of the event versus the unusualness of the event.

In this context the reliability is placed between the evidences created from the inductive data in favor of the evidence 'considered alone and by itself' and the records created by the uniform evidences of the nature against the reported event. We have 'proof against proof' with the reliability that cannot be achieved by any of the evidence individually, but from the result of their weighing against each other. After explaining the balancing of evidence, Hume reveals his maxim which is the culmination of this section:

"That no testimony is sufficient to establish a miracle, unless the testimony be of such a kind, that its falsehood would be more miraculous, than the fact, which it endeavours to establish ..." (Hume, 2007)

He seems to say that the necessary evidence to prove an event should go beyond a reasonable doubt, but in fact it is clear from the context that the witness would have to make the event probable:

When any one tells me, that he saw a dead man restored to life, I immediately consider with myself, whether it be more probable, that this person should either deceive or be deceived, or that the fact, which he relates, should really have happened. I weigh the one miracle against the other, and according to the superiority, which I discover, I pronounce my decision, and always reject the greater miracle. If the falsehood of his testimony would be more miraculous, than the event which he relates; then, and not till then, can he pretend to command my belief or opinion. (Hume,2007)

So here Hume assumes to make the possible balance that is most likely that the witness is lying or that event shows that he has really happened. And he expresses in a way his decision in favor of the possible event by rejecting the miracle. It follows that if the false testimony is unlikely that the alleged miracle "then ... can [the testifier] pretend to command my belief or opinion". (Hume, 2007)

Based on this reasoning, we can say that for Hume no evidence is sufficient to make a miracle more possible than impossible, except in cases where the witness is such that a false testimony of his, would be less possible that the fact that it tries to authenticate ... It seems that Hume puts into comparison the strength of human evidence with evidence of experience. It is quite obvious that concludes in his maxims that we should believe the testimony only if the probability that this evidence be false is smaller than the probability that the event has occurred.

Given that the formulations of natural laws and the formulation of their alleged violations fall into the category of matter of facts, the type of evidence required to support each formulation is the experience. However, even though the type of evidence required to justify the necessary two types of claims is the perception or observation in fundamental level, in Hume 's reasoning for laws of the nature, these generalizations require also an inductive support. In connection with the events of type $A$ and $B$ we are justified to believe that all $A$ 's are $B$, only if we have observed a sufficient number of A-s that are joined to B-s. The type of appropriate experience in order to justify a claim that a supposed natural law of the form 'all A 's are B-s ' is violated, is instead a single observation by someone that some A-s are not B-s. Hume seems to assume that none of his readers will not be able to experience such a prove. He discusses only cases in which we have knowledge only through witness' evidence - proof evidence provided by someone who claims to have seen a miracle. Thus the evidences supporting the allegations of natural laws are inductive and those supporting their violations are the observations or evidences.

Why does Hume think that an inductive evidence supporting a claim of a natural law is much stronger than an evidence of a testimony supporting the claim that the natural law has been violated? He affirms that the natural law are created from 'a firm and unalterable experience' and that, since 'a miracle is a violation of the laws of nature . . . the proof against a miracle . . . is as entire as any argument from experience can possibly be imagined' (Hume, 2007) He also says that there must 'be a uniform experience against every miraculous event' .

What is the test of experience stable against the natural laws, unchangeable and uniform (ie constant and without exception)? Even Hume does not answer this question in any detail, it appears that he has in mind the collective experience of human beings throughout history. Hume suggests that there is a natural law that dead people stay dead. He calls this a law of nature, for a dead has never been seen resurrected in human history. (Hume, 2007) Thus Hume obviously assumes that universal generalizations that form the natural laws are established and proven to be true on the basis of human experience in every time and every place. 
What can we say about those human beings who give us evidence that they have observed a violation of one of these universal generalizations? What can we say about such evidences of about 500 people claiming to have seen the resurrected Jesus after death? If their allegations are true, then Hume is wrong when he says that a person resurrected after death 'has never been observed in any age or country' (Hume, 2007). Hume is willing to accept the testimony of someone who can prove that there has been a violation of natural law. But for that to happen, the falsity of the testimony should be more exciting than the alleged miracle, for which the testimony is a proof. (Hume,2007). So, it can be reduced to what has most likely that the person who claims to have been witness to a miracle to be telling the truth than to be lying.

Hume gives us two reasons to think that, despite the theoretical possibility, a violation of the laws of nature can never be proven or tested based on the evidence. The first reason is that even would be more likely that a person who shows a violation of natural law is telling the truth rather than lying, the strength of evidence of testimony should be minimized by force of counterproof - which is the proof to claim that the said natural law has never been violated. The second reason Hume gives for his claim that there is no evidence of a violation of natural law is that there were never any strong sufficient evidence to support the conclusion that the reporters of miracles have more opportunity to be telling the truth rather than lying. The evidences did not prove and have not enabled the allegation of a miracle. Hume dedicates most part of the second part of the essay to the protection for this statement.

\section{Critics against Hume}

Many scholars criticize Hume's essay on miracles mainly based on the idea that his discussion of the miracle is incoherent with his inductive opinion and on causation.

Broad argues that by efforts to demonstrate knowledge of reality Hume presupposes causal reasoning, but causal reasoning is not based on any perception of the necessary links, but on an unreasonable expectation that as events in the past have continually been linked in the past, they will be connected in the future, as well. The fact that our past experience raises some expectations, gives us no reason to believe that these expectations will be met in the future. According to Broad, Hume forgets these arguments when discussing the miracles, in which some specific assumptions about natural laws are required. He argues here that the laws of nature are based on a stable and unchanging experience and renounce what he seems to accept that it is a strong evidence for miracles based on the claim that they are absolutely impossible events. The incoherence between discussion on miracles and previous discussions on induction and casualty is clear by Broad.

Jake Magee also rejects Hume's maxim on evidence of rejection of the evidence of miracles, because he thinks that Hume does not take into account the context from which can be treated this evidence of miracles. In his opinion, the miracles can be seen differently in different contexts such as: unlike in the context of religion, unlike in the context of naturalism etc. Therefore they cannot be dismissed.

Hambourger claims that Hume's argument is based on a principle called "the principle of relative probability." Against this principle, he requires us to assume that a lottery was held, in which there are 1 million tickets, the chance of which is 1 in 1 million to win the lottery, and that a serious newspaper, New York Times, reports that the winner of lottery is Smith. He asks us to assume that this newspaper is wrong in its reporting only once in 10 thousand times.

The possibility of newspaper reporting be wrong is greater than the possibility that Smith is the lottery's winner. If we apply this maxim of Hume for this example, we need to ponder the possibility that Smith is the winner against the possibility that the newspaper's report was wrong and come to the conclusion that it is more likely that newspaper has reported something untrue. But in fact it is more likely that the report of the newspaper be true according to Hambourger: the credibility of the newspaper should be evaluated based on how often this newspaper makes wrong reports, and whatever the statistical probabilities it is irrelevant to the assessment of its reliability. Hume's principled is therefore invalid. Hambourger argues that what we want to know in order to evaluate is the non-relative possibility that testimony is true. To assess newspaper's reporting we need to ask "How frequently are the Times' reports about lottery winners true?" and not "What is the probability of the event reported actually occurring?" so too in evaluating testimony about a miracle we should ask "How frequently are reports of miracles true?"(Hambourger,1980) "How frequently are reports of miracles true?" (Hambourger,1980) and not " What is the probability of the event occurring Reported actually ? " so too in evaluating testimony about a miracle we should askl "How frequently are reports of miracles true?" (Hambourger,1980). We cannot answer this based on the principle of Hume, who asks us to ponder the possibility of the occurrence of a miracle against the possibility that some miracle testimony is true. We can not factor out the plausibility of what one reports consider the remaining factors without it, and then, by weighing the two together, arrive at the probability that a 
report is true."(Hambourger,1980)"

\section{Conclusions}

I propose here that there is no incoherence in the opinion of Hume, and one can respond to these criticisms with the same arguments pointing out that Hume does not assume that there are not fallible natural laws and that cannot be facts against actual laws, but there are not miracles or events generated by a god and unexplained. Hume sees the miracle as an event that violates the natural law, that is divine and as a such is not understandable by humans. The main view of Hume is that because an event is incomprehensible to someone, does not mean that we come to the conclusion that it is a miracle. It is important to see the concept of Hume on cause (handled in the Treatise), because it is very important to understand his view. There are two definitions of causation: the first defines objectively in the terms of regularity (no necessary connection between events), the second defines the cause as a causal regularity, as opposed to the noncausal, for which we are prepared to use it for predictions. In this way, the need to distinguish the causal laws from noncausal ones is more subjective than objective. Not all causal judgments are rational, but we must distinguish the science from the superstition.

These judgments are rational, consistent with what Hume refers to as " the Rules by which to judge of causes and effects " ( Hume, 2004), ie types of induction. The thought is rational when it complies with the rules of induction rather than those of superstition, thus Hume offers us a practical justification for the rules of experimental science abolishing the best of our curiosity, interest on recognition etc. Hume believes that there may be a psychological explanation for all our beliefs: scientific and superstitious, but science is rationally justified. This protection of reason, according to Hume, is not a priori but a posteriori, so wrongful. Hume admits that it's always possible to have events that are contrary to the causal laws. The human mind can never achieve absolute certainty, because all causal judgments include the possibility to be wrong. Thus, Hume says that if I encounter an event that contradicts the natural laws (my past experience) it means that either the natural law is wrong, or I have to ask for an explanation, and it's not a miracle. The events that we do not understand, we should be explained through reason, and not superstition. There should be a law and an explanation for these events even though we do not know, but for Hume they are not unrecognizable. The fact that we encounter events that violate a regular pattern of our experience, gives us evidence that the model is not a law, but it doesn't reject the belief that there is a law that explains it. So an event can be strange and incomprehensible to us, but at the same time they do not oppose with the established course of nature. Since we can find exceptions that we have previously thought of as regularity that cannot prove that those events are miracles, that is, events that violate the laws of nature, but simply events that we do not understand and which has a logical explanation.

Recognizing that it is reasonable to accept the rules that determine the empirical reason, we accept that miracles are contrary to the reason. The reason in this sense is not infallible, but it cannot accept a miracle without destroying itself. Furthermore, the evaluation of reliability of the testimony is in itself a matter of empirical reason. To prove the reliability of an evidence we do not simply calculate probabilities, but by following a certain justification we make a decision based on the evidence we have and see if the testimony is logical proof or not. In the second part of the essay Hume assesses several issues. The first is that miracles were reported in a superstition period and not in a science one (Hume, 2007). Different religions try different miracles that have adverse consequences; in this context, these different religions eliminate each other by reducing the credibility of both. (Hume, 2007) There are various passions that make us breaking away from the rules of reason; we know that these are much more frequent than they low the reliability of the evidence of miracles. (Hume, 2007) And from the way they draw the human passion for the wonder, it's not a surprise that they are fascinating to people. Hume says that there is a natural tendency to accept miracles, but rather to satisfy passions than the curiosity. So, in the second part of the essay Hume puts the calculation of probabilities in a broader context of an analysis of the factors that are important to the truth or falsity of human testimonies.

Only experience gives right to the human testimony, and it's the same experience that gives us certainty about the laws of nature. Where these two experiences are in conflict, we can not do nothing but draw one from the other .

Critizers of Hume don't note that what they talk about might be surprising issues, unfamiliar, but not miracles. Haamburger takes an example of an event that has little chance of happening and not a miracle in the Hume's sense of miracle. It is important to say that Hume believes that there is a substantial difference between miracle and wonder. The difference lies in what strange events are repeatable and covered by the laws of nature. Consequently, they may not be understood now, but there must be an explanation for them. Hume thinks that miracles do not allow any condition under which the event can be observed. On the basis of this difference Hume suggests that there is strong evidence to guarantee belief regardles of the uniform experience when it comes to a surprising event. The probabilities are not 
schocked from the testimony, but we just do not know the true probabilities. When it comes to miracles, even the testimony of a higher quality is insufficient.

The science studies the phenomena which in former times were considered surprising (cases that Hume's critics take as counterexample of his theory) as cases that have not been explained yet, but for which, based on past experiences, we have good reasons, to believe that there were laws that explain them. This can not be said for miracles.

Hume has defended the view that all experiences lead to a consistent approach to reality, and science includes the requirement that every event has a cause, consequence as there is no room for a miracle occurred, and no evidence of reliability for a miracle: "a miracle , supported by any human testimony, (is) more properly a subject of derision than of argument. (Hume, 2007).

\section{References}

David Hume, "An Enquiry Concerning Human Understanding and Other Writings", Cambridge University Press, 2007.

David Hume, "Ricerca sull'intelleto umano", Editori Laterza, Classici della filosofia, con testo a fronte, 1996.

David Hume, "Treatise of Human Nature" Jonathan Bennett, Internet release 2004

David Hume, "The natural History of religion" The Writings of David Hume, ed. James Fieser (Internet Release, 1995)

Robert Hambourger, "Belief in Miracles and Hume's ESSaY," Nous 14 (1980): 587-604

Roy A. Sorensen, "Hume's Skepticism Concerning Reports of Miracles," Analysis 20 (1983).

Robert J. Fogelin. "A Defense of Hume on Miracles", Princeton and Oxford: Princeton University Press, 2003.

Dorothy Coleman, "Hume, Miracles, and Lotteries," Hume Studies 14.2 (1988): 343, n. 4.

C. D. Broad, "Hume's Theory of the Credibility of Miracles," Proceedings of the Aristotelian Society ns. 17 (1916-17).

Is It Irrational to Believe the Testimony of the Miraculous? A Critique of David Hume, Jake Magee 